\title{
Left ventricular epicardial lead placement after Carillon placement in the coronary sinus
}

\author{
C. A. da Fonseca · F. S. van den Brink · M. Feenema · K. Kraaier · T. N. Vossenberg
}

Published online: 1 July 2019

(c) The Author(s) 2019

A 72-year-old man with ischaemic cardiomyopathy and secondary mitral regurgitation developed heart failure. Due to the absence of options for revascularisation that would improve left ventricular function, poor functional status and a high Euro-SCORE II, the patient was deemed unfit for surgery. Furthermore, a cleft mitral valve also made him unsuitable for MitraClip [1]. To reduce mitral regurgitation he received treatment with a Carillon device for mitral valve annuloplasty in the coronary sinus (Fig. 1; [2]). Unfortunately, this did not reduce MR. In time he developed a left bundle branch block which made him eligible for placement of a cardiac resynchronisation therapy defibrillator (CRT-D) [3].

There were no complications and the patient's functional status improved significantly.
Conflict of interest C.A. da Fonseca, F.S. van den Brink, M. Feenema, K. Kraaier andT.N. Vossenberg declare that they have no competing interests.

Open Access This article is distributed under the terms of the Creative Commons Attribution 4.0 International License (http://creativecommons.org/licenses/by/4.0/), which permits unrestricted use, distribution, and reproduction in any medium, provided you give appropriate credit to the original author(s) and the source, provide a link to the Creative Commons license, and indicate if changes were made.

\section{References}

1. Katz WE, Smith AJC, Crock FW, Cavalcante JL. Echocardiographic evaluation and guidance for MitraClip procedure. Cardiovasc Diagn Ther. 2017;7(6):616-32. Dec.

2. Siminiak T, Wu J, Haude M, et al. Treatment of functional mitral regurgitation by percutaneous annuloplasty: results of the TITAN Trial. Eur J HeartFail. 2012;14(8):931-8.

3. Siminiak T, Jerzykowska O, Kalmucki P. Cardiac resynchronisation therapy after percutaneous trans-coronary-venous mitral annuloplasty. Kardiol Polska. 2013;71(12):1293-4. 


\title{
Advertisement placed here.
}

\author{
ces bohn \\ CL van loghum
}

Houten 2019 


\title{
Advertisement placed here.
}

\author{
ces bohn \\ CL van loghum
}

Houten 2019 


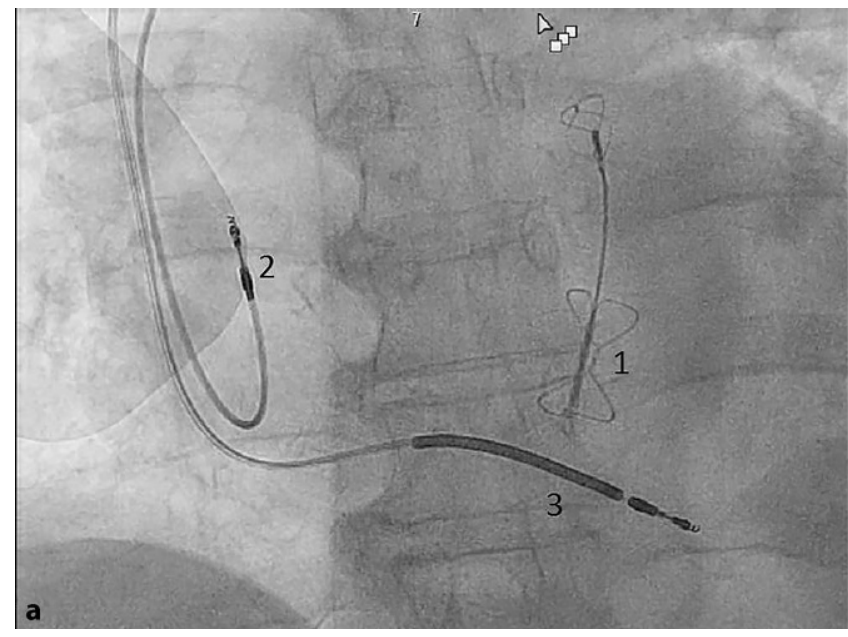

Fig. 1 a The Carillon device (1) with the right atrial (2) and right ventricular (3) leads; $\mathbf{b}$ the Carillon device (1) and the left ventricular epicardial lead (4) in the coronary sinus. This il-

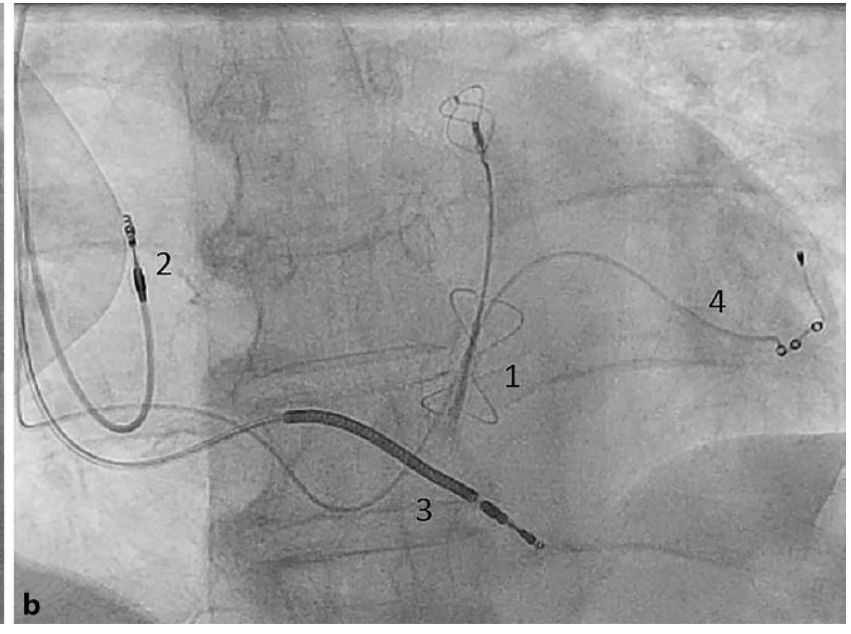

lustrates the possibility of placing a Carillon device and a left ventricular lead in the coronary sinus in the treatment of mitral regurgitation and heart failure 